\title{
SPATIAL MOBILITY OF STUDENTS IN A LARGE CITY ${ }^{1}$
}

\author{
Natalya L. Antonova \\ Ural Federal University, Yekaterinburg, Russian Federation \\ Sofya B. Abramova \\ Ural Federal University, Yekaterinburg, Russian Federation
}

\author{
Anna V. Anikieva \\ Institute of Education Development, Yekaterinburg, Russian Federation
}

\begin{abstract}
The proposed material is devoted to the sociological analysis of spatial mobility of students of a large industrial city. The article attempts to determine the theoretical and methodological boundaries of spatial mobility and fit it into the modern sociological discourse. Spatial mobility as an individually designed and socially determined phenomenon is associated with the process of constructing identity. Spatial identity is a dynamic nonlinear process, because, firstly, an individual simultaneously acts as a representative of different in composition, number and properties social groups and communities (including virtual); secondly, in the context of globalization and the expansion of cosmopolitan ideology, the coordinates and boundaries of space as the fundamental basis of the individual's self-consciousness are blurred.

The authors of the article focus on the study of factors and conditions that determine the readiness for mobility, the choice of the vector of spatial movement, as well as the evaluation of the attractiveness of the city as a place of residence and the implementation of students needs. The researchers characterize the dialectical and multifaceted choice of the desired and ideal place for young people to live, which becomes the basis for the participation of cities in the global competition for human resources. The lack of competitive advantages (opportunities for professional and personal self-realization, favorable environment, high income level of citizens, quality of life, developed leisure infrastructure) becomes a factor in the outflow of young people to more attractive areas.

The authors use the materials of a sociological study (2019), the object of which were the students of Ekaterinburg. Based on a standardized survey of students attended by 250 people (101 boys and 149 girls), as well 2 as 8 in-depth interviews with 4 girls and 4 boys, the paper argues that the factors of attractiveness of the city are ¿े conditions conducive to upward vertical mobility. The most attractive factors for choosing the vector of spatial mobility are economic (including professional), environmental and social and cultural stability, which creates conditions for the successful implementation of life plans, manifestations of initiative and innovative activity. O Choosing a city for the realization of their interests, students are guided by the ability of the territory to provide opportunities for informal interaction and freedom in the choice of everyday practices. These indicators form the basis for the formation of spatial identity through the symbolization of places, urban events and the experience of "collision" with the city.
\end{abstract}

Key words: spatial mobility, spatial identity, territory, city, attractiveness of the city, students.

\section{ПРОСТРАНСТВЕННАЯ МОБИЛЬНОСТЬ СТУДЕНЧЕСКОЙ МОЛОДЕЖИ} КРУПНОГО ГОРОДА ${ }^{1}$

\author{
Наталья Леонидовна Антонова
}

Уральский федеральный университет, г. Екатеринбург, Российская Федерация 


\section{Софья Борисовна Абрамова}

Уральский федеральный университет, г. Екатеринбург, Российская Федерация

\section{Анна Владимировна Аникиева}

Институт развития образования, г. Екатеринбург, Российская Федерация

Аннотация. Предлагаемый к рассмотрению материал посвящен социологическому анализу пространственной мобильности студентов крупного промышленного города. В статье предпринята попытка определить теоретико-методологические границы пространственной мобильности и вписать ее в современный социологический дискурс. Пространственная мобильность как индивидуально проектируемый и социально обусловленный феномен сопряжена с процессом конструирования идентичности. Пространственная идентичность представляет собой динамический нелинейный процесс, поскольку: во-первых, индивид одновременно выступает представителем различных по составу, численности и свойствам социальных групп и общностей (в том числе виртуальных); во-вторых, в условиях глобализации и распространения идеологии космополитизма координаты и границы пространства как фундаментальной основы самосознания индивида размываются. В статье сделан акцент на изучении факторов и условий, определяющих готовность к мобильности, выбор вектора пространственного перемещения, а также оценки привлекательности города как места проживания и реализации потребностей студенческой молодежи. Отсутствие конкурентных преимуществ (возможности профессиональной и личностной самореализации, благоприятная экология, высокий уровень доходов горожан, качество жизни, развитая досуговая инфраструктура) становится фактором оттока молодежи на более привлекательные территории.

В статье использованы материалы социологического исследования (2019), объектом которого стали студенты города Екатеринбурга. Опираясь на стандартизированный опрос студентов, в котором приняло участие 250 человек (101 юноша и 149 девушек), а также на 8 глубинных интервью с 4 девушками и 4 юношами, в работе утверждается, что факторами привлекательности города выступают условия, способствующие восходящей вертикальной мобильности. Наиболее привлекательными факторами выбора вектора пространственной мобильности выступают экономическая (в том числе профессиональная), экологическая и социокультурная устойчивость, создающие условия для успешной реализации жизненных планов, проявления инициативы и инновационной активности. При выборе города для реализации своих интересов студенты руководствуются способностью территории предоставить возможности для неформального взаимодействия и свободу в выборе практик повседневности. Эти показатели составляют базу для формирования пространственной идентичности через символизацию мест, городских событий и опыта «столкновения» с городом.

Ключевые слова: пространственная мобильность, пространственная идентичность, территория, город, привлекательность города, студенты.

\section{Введение}

Сегодня мобильность является одной из актуальных исследовательских проблем. Ее переосмысление и новое звучание связано с возникновением и развитием в конце XX столетия новой парадигмы мобильностей [Шеллер 2016], в предметном поле которой - многообразие мобильностей индивидов и объектов, а также их взаимозависимости и социальные эффекты [Sheller, Urry 2006]. В русле новой парадигмы акцентируется внимание не только на результат мобильности, но и на процессуальность перемещений, в ходе которых производятся и воспроизводятся социальные связи и отношения. Еще Г. Зиммель, рассматривая феномен движения в социальном пространстве, полагал, что анализ перемещений способствует созданию объяснительных моделей действий и взаимодействий индивидов, социальных групп и общностей [Simmel 1997].

В концепции П.А. Сорокина социальная мобильность определена как «любой переход индивида или социального объекта (ценности), то есть всего того, что создано или модифицировано человеческой деятельностью, из одной социальной позиции в другую» [Cорокин 1992, 292]. Такое толкование социальной мобильности широко тиражируется и считается классическим: определение воспроизводится в учебниках и учебных пособиях, а также в лексикографических источниках (словарях, энциклопедиях, справочниках).

Вместе с этим активная интенсификация перемещений индивидов и групп в физическом пространстве вследствие роста городов / ур- 
банизации, развития телекоммуникационных технологий актуализируют исследования пространственной мобильности. Отметим, что использование понятия пространственной мобильности более характерно для западной социологии [Favell, Recchi 2011] в контексте противопоставления социальной мобильности.

Пространственная мобильность в русле новой парадигмы мобильностей раскрывается в работах швейцарского социолога В. Кауфманна, в которых определена социальная обусловленность различных процессов, связанных с перемещениями (например, покидание молодыми людьми родительского дома как постоянного места жительства) [Kaufmann, Widmer 2006]. Автор выделил формы пространственной мобильности [Kaufmann 2011]: перемещения внутри / за пределы границ определенной территории (Within a population basin / Outside of population basin), а также длительность пребывания (Short temporalities / Long temporalities). $\mathrm{B}$ соответствии с типологией пространственная мобильность охватывает повседневную мобильность, путешествия / туризм, изменение места жительства (residental mobility) и миграцию. Миграция и изменение места жительства - это процессы, которые чаще всего сопряжены с изменением статусно-групповой принадлежности и, следуя логике П.А. Сорокина, находятся на стыке вертикальной и горизонтальной мобильности.

A. Келлерман [Kellerman 2012] развивает и радикализирует идеи В. Кауфманна, разделяя пространственную мобильность на два типа. Первый тип - повседневная мобильность, подразумевающая возвратность и регулярность. Второй тип - неповседневная мобильность. Этот тип перемещений включает в себя как возвратные перемещения (туризм), так невозвратные, связанные с изменениями социальной структуры (изменение места жительства, международная иммиграция).

В российской практике исследований пространственная мобильность зачастую понимается как миграция [Нефедова, Аверкиева, Махрова (ред.) 2016]. Так, например, Н.В. Мкртчян считает, что «пространственная мобильность включает как собственно миграцию, которая предполагает смену индивидом постоянного места жительства, так и временные, эпизодические перемещения, роль которых возрастает» [Мкртчян 2009, 150].

Вместе с тем, как справедливо отмечает А. Филиппов [Филиппов 2012], сегодня наблюдается сложность в понимании, интерпретации и идентификации процессов мобильности в физическом пространстве и мобильности в пространстве социальном. Так, идет активный исследовательский поиск в определении характеристик и качеств мобильной личности [Артюхова 2010], способной быстро реагировать и меняться [Артюшенко 2011] под воздействием социальной среды в соответствии с требованиями конкретной ситуации [Сергеева 2015]. Концептуально проблемное поле изучения мобильности выглядит открытым для дискуссии, содержательного наполнения и построения интерпретативных моделей.

\section{Методология и методика исследования}

Методологически целесообразно акцентировать внимание при анализе пространственной мобильности на ее свойства и характеристики, к числу которых относится возможность свободного перемещения. Ограниченный доступ к пространственной мобильности испытывают, например, пожилые и старые люди, несовершеннолетние дети, люди, имеющие недостатки в физическом и (или) психическом развитии. По сути это группа лиц, для которых самостоятельная пространственная мобильность становится вызовом, поскольку перемещение возможно только при сопровождении. Возможность свободно перемещаться согласно Дж. Урри включает и отказ от мобильности [Урри 2012].

Таким образом, движение «насыщается ценностями, нормами и властью» [Веселкова 2011] и является ресурсом, к которому различные социальные группы имеют неравный доступ. Соответственно, можно говорить о том, что доступность мобильности выступает фактором социальной стратификации, а реализация пространственной мобильности обнаруживает широкий спектр сценариев и интерпретаций, характерных для представителей различных социальных групп и общностей. Так, пространственная мобильность трудоспособного населения будет отличаться от 
перемещений молодежи, цель которой получить качественное образование в престижных университетах; мобильности замужних / женатых индивидов иные, нежели перемещения людей, не обремененных детьми и брачными узами. В современных условиях мобильность из средства превращается в самоценность [Веселкова 2011], формируется глобально мобильный класс, «новые номады» и «туристы» [Харламов 2012].

В. Кауфманн и В. Видмер выделяют мобильность (mobility) и подвижность / мотильность (motility). Последняя рассматривается ими как потенциал мобильности / капитал мобильности [Kaufmann, Widmer 2006]. К факторам, определяющим подвижность, относятся доступность (access) как возможность выбора альтернатив передвижения; умения и навыки (skills), необходимые для подвижности (поиск информации, способность адаптироваться к внезапным изменениям и т. д.), а также организаторские способности, позволяющие планировать деятельность; когнитивное усвоение (cognitive appropriation) как реализация навыков и умений, использование доступности подвижности. Когнитивное усвоение связано со стратегиями, ценностями, представлениями и привычками, которые формируются в процессе социализации и касаются усвоения общепринятых стандартов и ценностей [Flamm, Kaufmann 2006].

Пространственная мобильность, являясь индивидуально и социально обусловленной, сопряжена с процессом конструирования идентичности. Согласно И.Ю. Окуневу она «вытекает не из свойств места, а из его положения в пространстве, из системы его связей относительно других объектов [Окунев 2018, 22]. Пространственная идентичность является компасом в определении статуса и позиции территориального образования в системе геополитических, национальных, региональных координат. Речь идет о том, что историко-культурное прошлое служит ориентиром для формирования пространственной идентичности. Так, население Свердловской области может определять свою пространственную идентичность как проживающих на Родине первого Президента России. Сравнение места своего проживания с другими поселениями ведет к осознанию уникальности террито- рии и запускает механизмы воспроизводства идентичности. На локальном уровне появление и проявление чувства привязанности к территории происходит посредством выделения особых символических мест, наделяемых определенными смыслами и формирующих образ поселения [Nora 1984].

Пространственная идентичность выполняет функцию социальной защиты, она придает уверенность индивиду, формирует чувство безопасности [Giddens 1991]. Однако в современной «текучей действительности» (3. Бауман) пространственная идентичность все больше приобретает черты и свойства динамически нелинейного процесса. Это связано с тем, что, во-первых, индивид одновременно включен в различные по составу и характеристикам группы и общности, социальные институты и практики. Во-вторых, размываются координаты и границы пространства как базиса самосознания индивида, его укорененности. Идеология космополитизма все чаще становится определяющей современное положение индивида в условиях глобализации. О.В. Бочарова отмечает, что «мобильность содержится в умах людей, в знаниях, привычках, практических схемах» [Бочарова 2010, 103], что свидетельствует о снижении ценности «привязки» к определенному пространству и территории. Вместе с этим пространственная идентичность служит маркером, характеризующим отношение индивида к месту своего настоящего / текущего проживания, его установки и ориентации на пространственные перемещения.

Основной целью исследования стал анализ пространственной мобильности молодежи. Для реализации цели мы выдвинули следующие исследовательские задачи. Во-первых, определить факторы и условия пространственной мобильности молодежи; во-вторых, выявить особенности проявления пространственной идентичности молодого поколения; в-третьих, раскрыть ожидания молодежи от территории их будущего проживания.

Представленные в настоящей статье материалы являются результатом первого этапа исследования, объектом которого стала студенческая молодежь г. Екатеринбурга. Первичные данные были собраны с помощью стандартизированного опроса студентов, обу- 
чающихся по основным образовательным программам бакалавриата и магистратуры в университетах города. В опросе приняли участие 250 человек, из них: 101 юноша и 149 девушек. Также проведено 8 глубинных интервью с 4 девушками и 4 юношами. 58 \% респондентов - образовательные мигранты, то есть для них г. Екатеринбург не является городом их рождения. Студенты были опрошены в течение мая 2019 г. в свободное от образовательной деятельности время. Средняя продолжительность заполнения анкеты составила 15 минут. Авторы создали стандартизированный инструментарий для опроса, состоящий из 42 вопросов. Респондентам также была предоставлена возможность сформулировать собственное мнение, отвечая на открытые и полузакрытые вопросы. Полученные данные были обработаны при помощи пакета статистического анализа SPSS (версия 20).

\section{Результаты исследования}

Исследование позволило зафиксировать четыре основных направления оценивания города как привлекательной территории проживания: условия для экономической успешности, условия для проявления индивидуальности, инфраструктурная комфортность и широкая открытость социальных связей. При этом все направления имеют внутренне неоднозначный, зачастую противоречиво-дуальный характер.

Материальное благополучие и профессиональный успех составляют ядро представлений студентов о желаемом будущем. Фактор возможности профессионального роста является лидером при выборе города для жизни и важен для $61 \%$ опрошенных. При этом если деньги - чистый инструмент, рутина, то конечная цель описывается как «благополучие». И в этом контексте город становится определенным гарантом этого возможного благополучия. Он не только расширяет зону выбора профессии, рабочего места, условий труда; если территория маркируется как «благополучный город», «благополучный район» и т. п. - это создает позитивную установку и на личностный успех на данной территории.

При этом город должен быть в чем-то похож на самих молодых людей - это становится важным основанием для пространствен- ной идентичности. Если студенты характеризуют себя как активных и открытых, стремящихся к самореализации, то и город должен «откликаться» на эти потребности. «Смелость в выражениях взглядов, бунтарство, оно всегда было в молодых людях. Преимущество лучшего города - это открытость для всего нового, для инноваџий. Mbl не боимся, и город должен быть таким» (ж., 20). Город становится средой, в которой «невозможно лежать»: «...жить полной событиями жизнью. Вот раз там пошел погулял с друзьями, там сходил куда-нибудь, там или прокатился, в баню сходил... Ну, постоянно какие-то действия» (м., 21).

Активность развития города, «продвинутость» во многих сферах становится его значимым конкурентным преимуществом. В качестве «маркеров» активного города молодежь отмечает насыщенность культурными событиями и возможностями для саморазвития (мастер-классы, вебинары, спортивные сооружения и проч.), развитость торговой инфраструктуры [Антонова, Абрамова, Пименова 2019]. Оценивая Екатеринбург, опрошенные студенты в качестве сфер, лидирующих по развитию, указали предприятия общественного питания (кафе, бары, рестораны - 75 \%), сферу торговли (доступность товаров и услуг - $58 \%$ ), сферу культурного досуга (кино и театры - 46 \%).

Уверенность в неизбежности своего личного успеха - одна из базовых характеристик молодого поколения. В этой индивидуализированной картине один их основных страховостаться рядовым гражданином своего родного города: «Если выбирать какой-то путь, то нужно хотя бы надежду иметь и верить, что ты будешь в этом лучший. $А$ заурядным музыкантом в намем городе я не хочу быть. И предпочту уехать и рискнуть, чтобы стать лучшим» (м., 20).

$42 \%$ студентов готовы осуществить пространственную мобильность, встраивая смену места жительства в свои жизненные планы и соотнося возможности города со своими потребностями и целями. Такая предрасположенность формируется уже на уровне планов выпускников школ, особенно малых и средних городов, где преобладают тенденции к невозвратной миграции: основной вектор - более крупный город, а главный мотив - отсут- 
ствие возможностей в родном городе [Вандышев 2014].

Еще один дуализм «совершенного» города раскрывается в следующем контексте: город нового места жительства должен давать возможность не только продуцировать новые социальные сети, но и обеспечивать возможность поддержания прежних, прежде всего, родственных / семейных отношений. Пространственная мобильность рассматривается как качественный скачок в формировании своей самостоятельности и независимости, но при этом важно иметь возможность сохранить семейные традиции: «...летом или зимой, новогодние праздники мы традиционно, который год у бабушки, к ней приезжаем, такая традиция сформировалась, все вместе отдыхаем» (ж., 19). Территория должна быть легкодоступна: чтобы ее легко можно было как покинуть, так и вернуться обратно. Речь идет о развитой транспортной инфраструктуре, которая становится одним из базовых условий пространственной мобильности.

Выбор направления для пространственной мобильности и нового города для будущей жизни - многоаспектный процесс. Для оценки факторов, определяющих этот выбор, была использована шкала оценки от 1 до 4, где 1 означает очень низкую оценку критерия, а 4 - самую высокую. Система показателей представляла блоки вопросов, комплексно описывающих различные составляющие объективных условий города. В пятерку лидеров по оценке студентов вошли два показателя, связанные с условиями для профессиональной успешности (3,77 - возможность устроиться на работу, 3,46 - возможности профессионального роста и карьеры), фактор возможности саморазвития и самореализации $(3,61)$, а также два показателя, обеспечивающие базовую безопасность жизни $(3,56$ - доступность жилья, 3,53 - уровень экологической, криминальной и проч. безопасности). Также важно, чтобы город был насыщен «третьими местами» [Oldenburg 1999], давал возможность неформального общения и свободного выбора повседневных практик (3,45 - наличие зеленых зон и парков, 3,06 - наличие культурно-развлекательных учреждений, 3,06 - уровень и доступность учреждений общественного питания).

Каким образом формируется интерес к тому или иному пространству и территории?
Важное значение имеет информация, представленная в сети Интернет. Студенты смотрят сайты других городов, заводят себе друзей из разных университетов, «и мы уже знаем, нравится, не нравится им учиться, кто куда поступил, нравится, не нравится в том городе, какой опыт, как они стали там развиваться» (м., 21). Наличие друзей (даже виртуальных) из других городов подчеркивается респондентами как стартовое условие и моральная готовность: «...mbl уже видишь себя там, уже ходишь по этим улицам, и все не так страшно становится» (ж., 19).

Наконец, дуальность выбора города для совершения пространственной мобильности связана и с историческим контекстом территории. Большинство городов, которые приводятся в качестве «идеальных» вариантов (Москва, Санкт-Петербург, Казань, Амстердам, Берлин, Лондон, Мадрид, Рим, Стамбул) представляют собой исторические центры, под которыми информанты, с одной стороны, понимают классическую историю и сохранение культурно-исторического наследия - архитектуру, исторически сформировавшуюся красоту города (55 \%), наличие достопримечательностей как результат богатой истории города $(27 \%)$, а с другой - новейшую историю, выбирая города, где вершится современная судьба страны и мира (26 \% считают идеальным город с экономическим лидерством, $27 \%$ - с политическим).

Студенческая молодежь не хочет жить в «безликом» городе. Если стать частью «сильного, исторического города», через принадлежность к нему можно в будущем увидеть свою сопричастность к изменениям, ощутить одновременность жизни города и человека в нем: «Он растет, меняется вместе со мной, мне будет приятно на него через 10 лет посмотреть, как он меняется» (ж., 21). Это чувство становится одним из базовых при формировании пространственной идентичности как индикатора самосознания.

Результаты исследования показали, что $40 \%$ опрошенных считают себя в первую очередь жителями города Екатеринбурга. Этот показатель, по нашему мнению, отражает реальный факт проживания на конкретной территории и свидетельствует о том, что студенты становятся субъектами развития простран- 
ства проживания. Практически каждый четвертый респондент чувствует себя россиянином. В этом ракурсе принадлежность к большой социальной общности определяет как мировоззренческие позиции, так и поведенческие практики молодого поколения. $22 \%$ респондентов заявили свою пространственную идентичность в планетарном масштабе. Ответы студентов демонстрируют четкий вектор пространственной идентичности: от локальной идентичности к глобальной.

В процедуре измерения локальной идентичности студенческой молодежи мы обратились к респондентам с вопросом о выделении мест в пространстве города, его символизирующих. Материалы опроса показали, что лидирующее положение занимают набережная реки Исеть («Плотинка») - 88 \%, центральная городская площадь («Площадь 1905 года») $56 \%$, Президентский центр Б.Н. Ельцина («Ельцин-центр») - 50 \%. Все указанные локальные точки на карте города расположены в центральной его части и по сути выступают публичными / полупубличными местами, peaлизующими широкий спектр функций. Важно отметить, что студенты приписывают этим местам символическое значение и включают в маршруты повседневных перемещений. $3 / 4$ респондентов отмечают указанные выше точки как любимые места для прогулок и встреч с друзьями. Таким образом, наблюдается следующая связь: чем чаще индивид проходит / пересекает определенные места в повседневных перемещениях, тем чаще они становятся метками его «привязки» к городу.

Пространственная идентичность формируется не только через систему символических мест, но и через событийный ряд, который задает уникальность и значимость территории для индивида, образуя чувство сопричастности. При этом события могут иметь как позитивную, так и негативную окраску. В нашем исследовании в пространственной идентичности студентов выделены оба аспекта. Так, для $55 \%$ опрошенных город определен как территория проведения Чемпионата мира по футболу 2018 г., а для 40 \% респондентов - как место гибели царской семьи.

Важным механизмом поддержания и закрепления пространственной идентичности выступает регулярное воспроизводство зна- чимых для индивидов и групп событий и их устойчивость. Наибольшая доля респондентов считает таким событием День города (57 \%). Это событие, как правило, ежегодно привлекает внимание значительной доли горожан и вовлекает их в различные мероприятия, нацеленные на удовлетворение широкого спектра потребностей и интересов, уверенно демонстрируя возможность непосредственного участия каждого жителя в создании и поддержании традиций. При этом происходит закрепление идентичности и с общностью горожан, и с территорией.

Показателем закрепления пространственной идентичности является и готовность рекомендовать город для потенциальной мобильности своих друзей, родственников, знакомых. 57 \% участников проекта имеют четко сформированное мнение, что они стали бы рекомендовать, и только для $14 \%$ Екатеринбург не представляется городом, достойным рекомендации.

\section{Заключение}

В целом, опираясь на проведенный анализ, можно сделать следующие выводы.

Пространственная мобильность современной студенческой молодежи определяется ее представлениями о возможностях территории стать платформой старта карьеры в соответствии с жизненными сценариями. Образ привлекательной территории тесно связан с представлениями студентов об их индивидуальной успешности и независимости. Это не может быть «простой, спокойный» и «абсолютно безопасный» город, поскольку в этих условиях не будет востребована инновационная активность молодежи. Территория должна быть стабильно благополучной, давать гарантии экономической, экологической, социокультурной устойчивости, что определяет стратегические направления политики в области планирования и проектирования пространства.

Вектор пространственной идентичности студентов определяется от локальной (екатеринбуржец) к глобальной (землянин). Условиями формирования, закрепления и воспроизводства пространственной идентичности являются включение в повседневные перемещения определенных мест, наделенных инди- 
видуальными и / или групповыми смыслами, участие в текущих культурных (массовых) событиях, а также историческое прошлое территории, имеющее социальную ценностную значимость.

Диалектичность представлений о городе своей будущей жизни определяет поисковый, неопределенный характер траектории мобильности. Потенциальная готовность к перемещениям, формируемая в школьный период на стандартизированных стереотипных представлениях об идеальных городах, в студенческий период начинает опираться на систему рациональных показателей, предварительный сбор и анализ информации. Это позволяет включить модель принятия решения о пространственной мобильности в систему различных муниципальных, региональных и федеральных программ.

\section{ПРИМЕЧАНИЕ}

${ }^{1}$ Исследование выполнено при финансовой поддержке РФФИ и АНО ИЭСИ в рамках научного проекта № 19-011-31151 «Привлекательность территории как фактор пространственной мобильности молодежи: образы будущего и настоящего».

The study was conducted with the financial support of RFBR and ANCO EISR, project no. 19-01131151 "Territory attractiveness as the factor of spatial mobility of the young: images of future and present".

\section{СПИСОК ЛИТЕРАТУРЫ}

Антонова, Абрамова, Пименова 2019 - Антонова Н.Л., Абрамова С.Б., Пименова О.И. Привлекательность города как фактор территориальной мобильности в оценках студентов (на примере города Екатеринбурга) // Образование и наука. 2019. Т. 21, № 1. C. 97-123. DOI: 10.17853/1994-5639-2019-1-97-123.

Артюхова 2010 - Артюхова Т.Ю. Психологические характеристики мобильной личности // Международный журнал экспериментального образования. 2010. № 7. С. 96-98.

Артюшенко 2011 - Артюшенко А. А. Личностная мобильность и ее формирование у учащихся в процессе физического воспитания в общеобразовательной школе // Педагогика, психология и медико-биологические проблемы физического воспитания и спорта. 2011. № 8. С. 6-11.

Бочарова 2010 - Бочарова О.В. Истоки институциализации городского общественного транс- порта // Теория и практика общественного развития. 2010. № 3. С. 102-106.

Вандышев 2014 - Вандылее М.Н. Потенциальная мобильность выпускников школ малых и средних городов Свердловской области // Мониторинг общественного мнения: экономические и социальные перемены. 2014. № 5 (123). C. 114-124. DOI: 10.14515/monitoring.2014.5.06.

Веселкова 2011 - Веселкова Н.В. Новые исследования мобильности: совпадающие и несовпадающие потоки и социальная компетентность // Журнал социологии и социальной антропологии. 2011. Т. 14, № 3. С. 50-66.

Нефедова, Аверкиева, Махрова (ред.) 2016-Нефедова Т.Г., Аверкиева К.В., Махрова А.Г. (ред.). Между домом... и домом. Возвратная пространственная мобильность населения России. М.: Новый хронограф, 2016.

Мкртчян 2009 - Мкртчян Н.В. Миграционная мобильность в России: оценки и проблемы анализа // SPERO. 2009. № 11. С. 149-164.

Окунев 2018 - Окунев И.Ю. Территориальная и пространственная идентичность: концептуализация базовых понятий // Сравнительная политика. 2018. Т. 9, № 1. С. 18-25. DOI: 10.24411/ 2221-3279-2018-00002.

Сергеева 2015 - Сергеева Т.Б. Личностная и профессиональная мобильность: проблема сопряженности // Образование и наука. 2015. № 8 (127). C. 81-96. DOI: 10.17853/1994-56392015-8-81-96.

Сорокин 1992 - Сорокин П.А. Человек. Цивилизация. Общество. М.: Политиздат, 1992.

Урри 2012 - Урри Дж. Мобильности. М.: Праксис, 2012.

Филиппов 2012 - Филиппов А. Парадоксальная мобильность // Отечественные записки. 2012. № 5(50). C. 8-23.

Харламов 2012 - Харламов Н. Пространство мобильного мира // Отечественные записки. 2012. № 5 (50). C. 95-108.

Шеллер 2016 - Шеллер М. Новая парадигма мобильностей в современной социологии // Социологические исследования. 2016. № 7. C. 3-11.

Favell, Recchi 2011 - Favell A., Recchi E. Social Mobility and Spatial Mobility// Sociology of the European Union. Basingstoke: Palgrave Macmillan, 2011. P. 50-75.

Flamm, Kaufmann 2006 - Flamm M., Kaufmann V. Operationalising the Concept of Motility: A Qualitative Study// Mobilities. 2006. Vol. 1, iss. 2. P. 167-189. DOI: 10.1080/17450100600726563.

Giddens 1991 - Giddens A. Modernity and Selfidentity: Self and society in late modern age. Cambridge: Polity Press, 1991. 
Kaufmann, Widmer 2006 - Kaufmann V., Widmer E.D. Motility and family dynamics: Current issues and research agendas // Zeitschrift für Familienforschung. 2006. Iss. 1. P. 111-130.

Kaufmann 2011 - Kaufmann $V$. Rethinking the city: urban dynamics and motility. Lausanne: EPFL Press, 2011.

Kellerman 2012 - Kellerman A. Daily spatial mobilities: physical and virtual. Farnham; Burlington: Ashgate, 2012.

Nora 1984 - Nora P. Les lieux de mémoire. La République, la Nation, les France. Paris: Gallimard, 1984.

Oldenburg 1999-Oldenburg $R$. The Great Good Place: Cafes, Coffee Shops, Bookstores, Bars, Hair Salons, and Other Hangouts at the Heart of a Community. N.Y.: Marlowe, 1999.

Sheller, Urry 2006 - Sheller M., Urry J. The new mobilities paradigm// Environment and Planning. 2006. Vol. 38. P. 207-226. DOI: 10.1068/a37268.

Simmel 1997 - Simmel G. Sociology of the Senses // Simmel On Culture: Selected Writings. L.: Sage, 1997. P. 109-119.

\section{REFERENCES}

Antonova N.L., Abramova S.B., Pimenova O.I., 2019. Attractiveness of a city as a factor of territorial mobility in student estimates (on the example of Ekaterinburg). Obrazovanie i nauka, vol. 21, no. 1,pp.97-123. DOI: 10.17853/1994-5639-20191-97-123.

Artjuhova T.Ju., 2010. Psychological characteristics of mobile personality. Mezhdunarodnyj zhurnal jeksperimental'nogo obrazovanija, no. 7, pp. $96-98$

Artjushenko A.A., 2011. Personal mobility and its formation in students in the process of physical education in secondary school. Pedagogika, psihologija $i$ medikobiologicheskie problemy fizicheskogo vospitanija i sporta, no. 8, pp. 6-11.

Bocharova O.V., 2010. The origins of the institutionalization of urban public transport. Teorija i praktika obshhestvennogo razvitija, no. 3, pp. 102-106.

Vandyshev M.N., 2014. Potential mobility of graduates of schools in small and medium-sized cities of the Sverdlovsk region. Monitoring obshhestvennogo mnenija: jekonomicheskie i social'nye peremeny, no. 5 (123), pp. 114-124. DOI: 10.14515/ monitoring.2014.5.06.

Veselkova N.V., 2011. New mobility studies: coincident and non-coincident flows and social competence. Zhurnal sociologii $i$ social'noj antropologii, vol. 14, no. 3, pp. 50-66.
Nefedova T.G., Averkieva K.V., Makhrova A.G. (ed.), 2016. Between the home ... and the home. Returnable spatial mobility of the population of Russia. Moscow, New chronograph.

Mkrtchjan N.V., 2009. Migracionnaja mobil'nost' v Rossii: ocenki i problemy analiza. SPERO, no. 11, pp. 149-164.

Okunev I.Ju., 2018. Territorial and spatial identity: conceptualization of basic concepts. Sravnitel'naja politika, vol. 9, no. 1, pp. 18-25. DOI: 10.24411/2221-3279-2018-00002.

Sergeeva T.B., 2015. Personal and professional mobility: the problem of contingency. Obrazovanie i nauka, no. 8 (127), pp. 81-96. DOI: 10.17853/1994-5639-2015-8-81-96.

Sorokin P.A., 1992. Person. Civilization. Society. Moscow, Politizdat.

Urry J., 2012. Mobilities. Moscow, Praksis.

Filippov A., 2012. Paradoxical mobility. Otechestvenny'e zapiski, no. 5 (50), pp. 8-23.

Harlamov N., 2012. Mobile world space. Otechestvenny'e zapiski, no. 5 (50), pp. 95-108.

Sheller M., 2016. New paradigm of mobility in modern sociology. Sociologicheskie issledovanija, no. 7, pp. 3-11.

Favell A., Recchi E., 2011. Social Mobility and Spatial Mobility. Sociology of the European Union. Basingstoke, Palgrave Macmillan, pp. 50-75. DOI: 10.1007/978-0-230-34390-0_3.

Flamm M., Kaufmann V., 2006. Operationalising the Concept of Motility: A Qualitative Study. Mobilities, vol. 1, iss. 2, pp. 167-189.

Giddens A., 1991. Modernity and Self-identity: Self and society in late modern age. Cambridge, Polity Press.

Kaufmann V., Widmer E., 2006. Motility and family dynamics: Current issues and research agendas. Zeitschrift für Familienforschung, no. 1, pp. 111-130.

Kaufmann V., 2011. Rethinking the city: urban dynamics and motility. Lausanne, EPFL Press.

Kellerman A., 2012. Daily spatial mobilities: physical and virtual. Farnham; Burlington, Ashgate.

Nora P., 1984. The places of memory. The Republic, the Nation, France. Paris, Gallimard.

Oldenburg R., 1999. The Great Good Place: Cafes, Coffee Shops, Bookstores, Bars, Hair Salons, and Other Hangouts at the Heart of a Community. New York, Marlowe.

Sheller M., Urry J. 2006. The new mobilities paradigm. Environment and Planning, vol. 38, pp. 207226. DOI: $10.1068 / \mathrm{a} 37268$.

Simmel G., 1997. Sociology of the Senses. Simmel On Culture: Selected Writings. London, Sage, pp. 109-119. 
Н.Л. Антонова, С.Б. Абрамова, А.В. Аникиева. Пространственная мобильность студенческой молодежи

\section{Information about the Authors}

Natalya L. Antonova, Doctor of Sciences (Sociology), Professor, Department of Applied Sociology, Ural Federal University, Prosp. Lenina, 51,620075 Yekaterinburg, Russian Federation, n-tata@mail.ru, https://orcid.org/0000-0002-2063-4970

Sofya B. Abramova, Candidate of Sciences (Sociology), Associate Professor, Department of Applied Sociology, Ural Federal University, Prosp. Lenina, 51, 620075 Yekaterinburg, Russian Federation, sofia_abramova@mail.ru, https://orcid.org/0000-0003-4010-8406

Anna V. Anikieva, Candidate of Sciences (Sociology), Specialist, Department of Education Studies, Institute of Education Development, Academicheskaya St., 16, 620066 Yekaterinburg, Russian Federation, anutadanilova@ya.ru, https://orcid.org/0000-0002-8440-8163

\section{Информация об авторах}

Наталья Леонидовна Антонова, доктор социологических наук, профессор кафедры прикладной социологии Уральского гуманитарного института, Уральский федеральный университет, просп. Ленина, 51, 620075 г. Екатеринбург, Российская Федерация, n-tata@mail.ru, https://orcid.org/0000-0002-2063-4970

Софья Борисовна Абрамова, кандидат социологических наук, доцент кафедры прикладной социологии Уральского гуманитарного института, Уральский федеральный университет, просп. Ленина, 51, 620075 г. Екатеринбург, Российская Федерация, sofia_abramova@mail.ru, https://orcid.org/0000-0003-4010-8406

Анна Владимировна Аникиева, кандидат социологических наук, специалист отдела исследований состояния системы образования, Институт развития образования, ул. Академическая, 16, 620066 г. Екатеринбург, Российская Федерация, anutadanilova@ya.ru, https://orcid.org/0000-0002-8440-8163 